Article

\title{
Individual and Combined Effect of Zearalenone Derivates and Beauvericin Mycotoxins on SH-SY5Y Cells
}

\author{
Fojan Agahi, Guillermina Font, Cristina Juan * and Ana Juan-García@ \\ Laboratory of Food Chemistry and Toxicology, Faculty of Pharmacy, University of Valencia, Av. Vicent Andrés \\ Estellés s/n, 46100 Burjassot, València, Spain; agahifozhan@gmail.com (F.A.); guillermina.font@uv.es (G.F.); \\ ana.juan@uv.es (A.J.-G.) \\ * Correspondence: cristina.juan@uv.es
}

Received: 9 February 2020; Accepted: 25 March 2020; Published: 27 March 2020

\begin{abstract}
Beauvericin (BEA) and zearalenone derivatives, $\alpha$-zearalenol ( $\alpha$-ZEL), and $\beta$-zearalenol $(\beta-Z E L)$, are produced by several Fusarium species. Considering the impact of various mycotoxins on human's health, this study determined and evaluated the cytotoxic effect of individual, binary, and tertiary mycotoxin treatments consisting of $\alpha$-ZEL, $\beta$-ZEL, and BEA at different concentrations over 24,48 , and $72 \mathrm{~h}$ on SH-SY5Y neuronal cells, by using the MTT assay (3-(4,5-dimethylthiazol-2-yl)-2,5diphenyltetrazoliumbromide). Subsequently, the isobologram method was applied to elucidate if the mixtures produced synergism, antagonism, or additive effects. Ultimately, we determined the amount of mycotoxin recovered from the media after treatment using liquid chromatography coupled with electrospray ionization-quadrupole time-of-flight mass spectrometry (LC-ESI-qTOF-MS). The $\mathrm{IC}_{50}$ values detected at all assayed times ranged from 95 to $0.2 \mu \mathrm{M}$ for the individual treatments. The result indicated that $\beta$-ZEL was the most cytotoxic mycotoxin when tested individually. The major effect detected for all combinations assayed was synergism. Among the combinations assayed, $\alpha$-ZEL $+\beta$-ZEL + BEA and $\alpha$-ZEL + BEA presented the highest cytotoxic potential with respect to the IC value. In individual treatment, $\alpha$-ZEL was the most recovered mycotoxin; while, this was observed for BEA in binary combination $\alpha$-ZEL + BEA.
\end{abstract}

Keywords: SH-SY5Y cells; zearalenone derivates; beauvericin; MTT; qTOF-MS/MS

Key Contribution: Individual exposure of $\beta$-ZEL in SH-SY5Y cells presented the highest cytotoxicological potency compared to $\alpha$-ZEL and BEA; while in combination, $\alpha$-ZEL $+\beta$-ZEL + BEA and $\alpha$-ZEL + BEA presented the highest cytotoxic potential with respect to the IC50 value obtained. Recoveries were the highest for $\alpha$-ZEL in individual treatment in SH-SY5Y; while, this high recovery was observed for BEA in binary combination $\alpha$-ZEL + BEA.

\section{Introduction}

Mycotoxins represent one of the most important categories of biologically produced natural toxins with potential effects on human and animal health. The worldwide contamination by these natural products of food, feed, and environment, represents a health risk for animals and humans [1].

Several Fusarium species produce toxic substances of considerable concern to livestock and poultry producers. The mycotoxins beauvericin (BEA) and zearalenone (ZEN) and their derivatives ( $\alpha$-zearalenol ( $\alpha$-ZEL), $\beta$-zearalenol ( $\beta$-ZEL), zeranol, taleranol, and zearalanone) can be produced by several Fusarium species (mainly Fusarium graminearum, but also Fusarium culmorum, Fusarium cerealis, Fusarium equiseti, and Fusarium semitectum) that grow on crops in temperate and warm-climate zones [2]. 
These fungi are present in almost all continents, can grow under poor storage conditions, and mainly contaminate cereal grains, such as maize, wheat, oats, soybeans, and their derived food products $[3,4]$.

It has been proved that ZEN and $\alpha$-ZEL bind to human estrogen receptors and elicit permanent reproductive tract alterations, and consequently, chronical exposure to ZEN present contaminated food can be a cause of female reproductive changes as a result of its powerful estrogenic activity [5-8]. It has been also reported that ZEN induces genotoxic effects by induction of DNA adducts, DNA fragmentation, and apoptosis [9,10]. As reported by Dong et al. (2010) [5], metabolic conversion of ZEN mycotoxin to $\alpha$-ZEL and $\beta$-ZEL was found in almost all tissues and occurred more efficiently to $\alpha$-ZEL than to $\beta$-ZEL; these mycotoxins are endocrine disruptors which affect steroid hormones such as progesterone [7]. In 2016, EFSA (European food Safety Authorities) indicated that there is a high uncertainty associated with the exposure to ZEN and its modified forms and so that it would rather overestimate than underestimate any risk associated with exposure to modified ZEN [8]. Also, recent studies have indicated that ZEN is immunotoxic $[4,11,12]$ and cytotoxic in various cell lines by inhibiting cell proliferation and increasing ROS (reactive oxygen species) generation [13-15].

On the other hand, BEA causes cytotoxic effects by reducing cell proliferation in a timeand concentration-dependent manner [16,17]. Moreover, it can increase ROS generation and lipid peroxidation and produces oxidative stress and depletion of antioxidant cellular mechanisms $[14,18,19]$.

Neurotoxicological testing is mainly based on experimental animal models, but several cell lines and tissue culture models have been developed to study the mechanism of neurotoxicity. In general, cells of human origin are attractive alternatives to animal models for the exploration of toxicity to humans. Nonetheless, there are few studies about the effect of mycotoxins at the neuronal level [6,20-22].

Regarding the important role of the food industry in human health, studying the impact of mycotoxins and their combinations in feed and food commodities has gained attention over the last few years, due to the ability of most Fusarium spp. to simultaneously produce different mycotoxins [23-25]. Hence, EFSA has recently published a draft guidance document where a harmonized risk assessment methodology for combined exposure to multiple chemicals in all relevant areas is described [26].

Due to the importance of dietetic exposure to various mycotoxins and their impacts on human's health, there is an increasing concern about the hazard of co-occurrence of mycotoxins produced by Fusarium and of co-exposure to them through diet. Many studies have been conducted on the toxicity of individual mycotoxins; however, few studies have been dedicated to the toxicological interaction of mycotoxins when present in double and triple combinations on different cell lines [16-18,27-29].

The objective of the present study was to investigate the cytotoxicological interactions between $\alpha$-ZEL, $\beta$-ZEL, and BEA mycotoxins in human neuroblastoma SH-SY5Y cells, via the MTT assay. The effects of combinations of two and three mycotoxins were evaluated by isobologram analysis [30] to determine whether their interaction was synergistic, additive, or antagonistic, as well as to understand how mycotoxins can act at the cellular level.

\section{Results}

\subsection{Cytotoxicity Assay of Individual and Combined Mycotoxins}

The cytotoxicity effects of $\alpha$-ZEL, $\beta$-ZEL, and BEA mycotoxins on SH-SY5Y cells were evaluated by the MTT assays over 24, 48, and $72 \mathrm{~h}$. Figure 1 shows the time- and concentration-dependent decrease in cell viability after exposure to each mycotoxin individually, while $\mathrm{IC}_{50}$ values are shown in Table 1 . After $24 \mathrm{~h}$, the $\mathrm{IC}_{50}$ value could be calculated only for $\beta$-ZEL and was $94.3 \pm 2.0 \mu \mathrm{M}$; after $48 \mathrm{~h}$ of exposure, the $\mathrm{IC}_{50}$ values were $20.8 \pm 0.5 \mu \mathrm{M}$ for $\alpha$-ZEL and $9.1 \pm 1.8 \mu \mathrm{M}$ for $\beta$-ZEL. After $72 \mathrm{~h}$ of exposure, the $\mathrm{IC}_{50}$ values were $14.0 \pm 1.8 \mu \mathrm{M}, 7.5 \pm 1.2 \mu \mathrm{M}$. and $2.5 \pm 0.2 \mu \mathrm{M}$ for $\alpha$-ZEL, $\beta$-ZEL, and BEA, respectively. According to the $\mathrm{IC}_{50}$ values obtained at $72 \mathrm{~h}, \mathrm{BEA}$ showed the highest cytotoxic effect on SH-S5Y5 cells (Table 1). 
a)

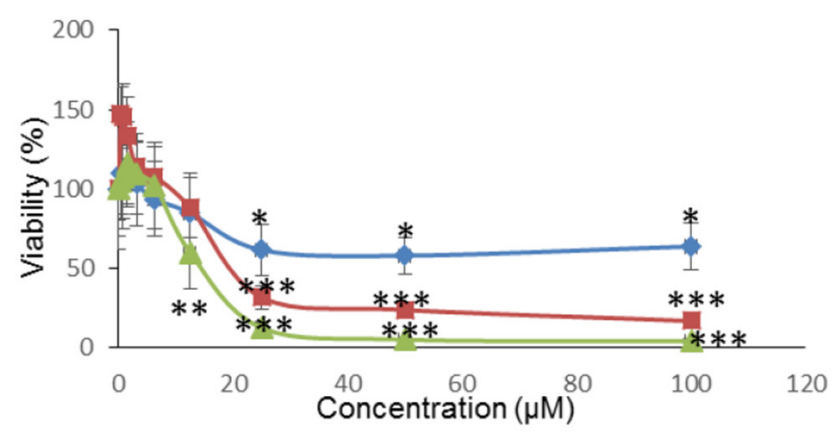

b)

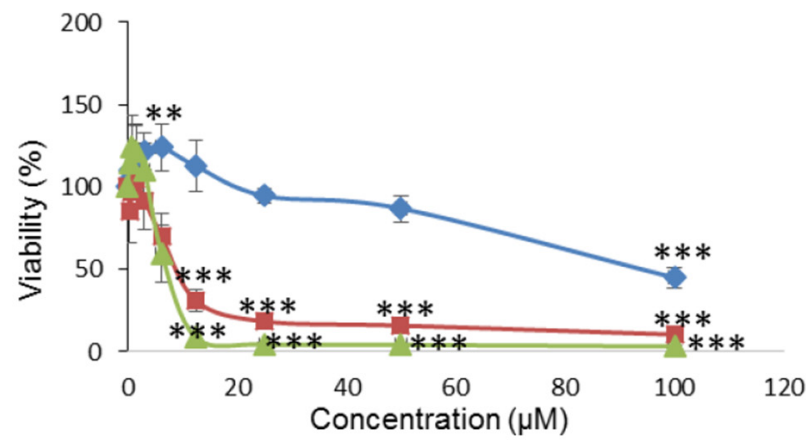

c)

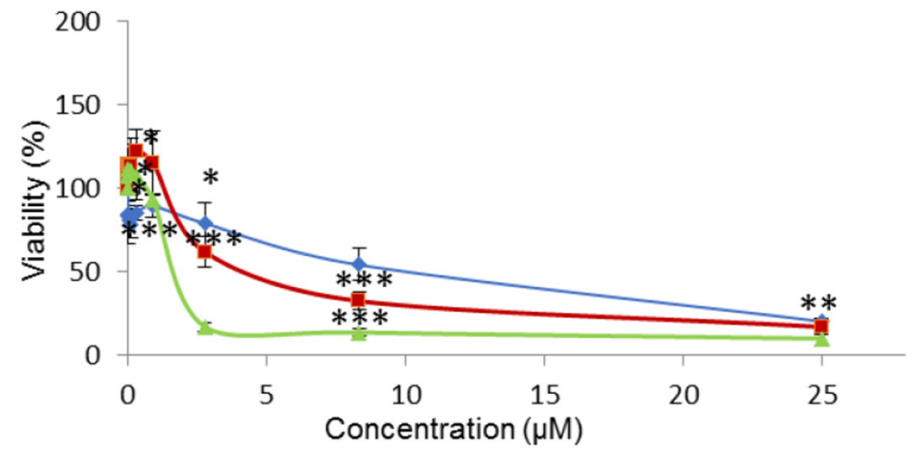

Figure 1. Cytotoxicity of the mycotoxins $\alpha$-ZEL (a), $\beta$-ZEL (b), and BEA (c) individually at $24 \mathrm{~h}, 48 \mathrm{~h}$, and $72 \mathrm{~h}$. All values are the results of three independent experiments with eight replicates and are expressed as mean $\pm \mathrm{SD} ; p \leq 0.05\left(^{*}\right), p \leq 0.01\left(^{* *}\right), p \leq 0.001\left(^{* * *}\right)$.

Table 1. Medium inhibitory concentration ( $\mathrm{IC}_{50} \pm \mathrm{SD}$ ) of $\alpha$-zearalenol $(\alpha$-ZEL), $\beta$-zearalenol $(\beta$-ZEL), and beauvericin (BEA) for SH-SY5Y cells after 24,48 , and $72 \mathrm{~h}$ of exposure, determined by the MTT assay. Three independent experiments were performed with eight replicates each.

\begin{tabular}{lccc}
\hline \multirow{2}{*}{ Mycotoxin } & \multicolumn{3}{c}{ IC $_{\mathbf{5 0}}(\boldsymbol{\mu M}) \pm \mathbf{S D}$} \\
\cline { 2 - 4 } & $\mathbf{2 4} \mathbf{h}$ & $\mathbf{4 8 ~ h}$ & $\mathbf{7 2 ~ h}$ \\
\hline$\alpha$-ZEL & n.a & $20.8 \pm 0.5$ & $14.0 \pm 1.8$ \\
$\beta$-ZEL & $94.3 \pm 2.0$ & $9.1 \pm 1.8$ & $7.5 \pm 1.2$ \\
BEA & n.a & n.a & $2.5 \pm 0.2$ \\
\hline \multicolumn{4}{c}{ n.a: not available. }
\end{tabular}

The cytotoxic effect of binary and tertiary combinations of $\alpha$-ZEL, $\beta$-ZEL, and BEA on SH-SY5Y cells was evaluated by the MTT assays over 24,48 , and $72 \mathrm{~h}$. The dose-response curves of the two- and three-mycotoxin combinations are shown in Figures 2 and 3, which demonstrate higher cytotoxicity of the combinations compared with individual mycotoxin. Figure 2 shows the concentration-dependent decrease in SH-SY5Y cell viability upon combined treatment with $\alpha$-ZEL + BEA (5:1) (Figure 2a), $\beta$-ZEL + BEA (5:1) (Figure 2b), $\alpha$-ZEL + $\beta$-ZEL (1:1) (Figure 2c); Figure 3 shows the results for $\alpha-Z E L+\beta-Z E L+\operatorname{BEA}(5: 5: 1)$. 
a)

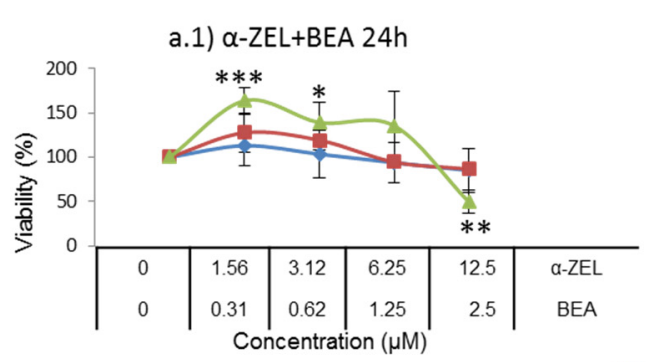

b)

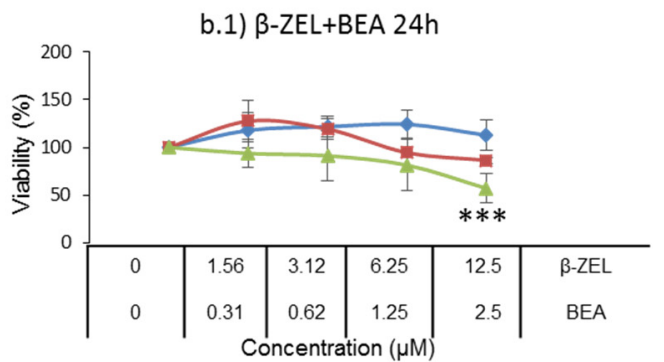

c)

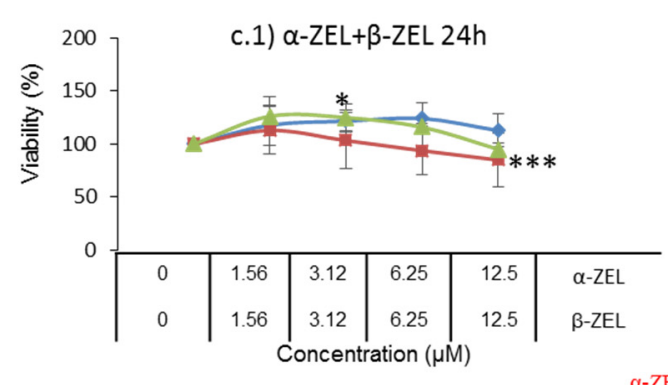

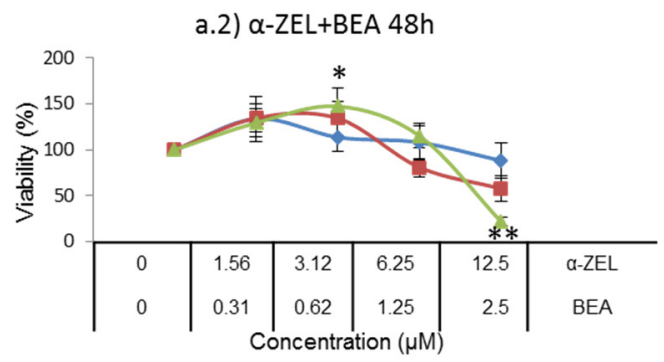

BEA: line and square; $\alpha$-ZEL: line and diamond; Mixture: line and triangle

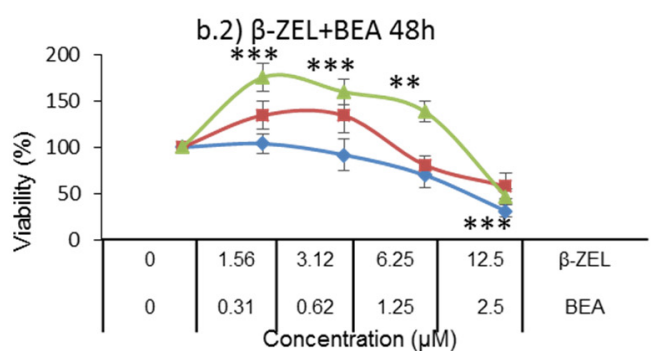

BEA: line and square; $\beta$-ZEL: line and diamond; Mixture: line and triangle

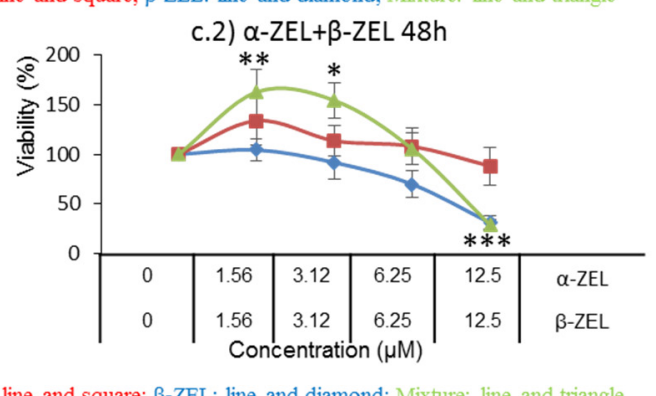

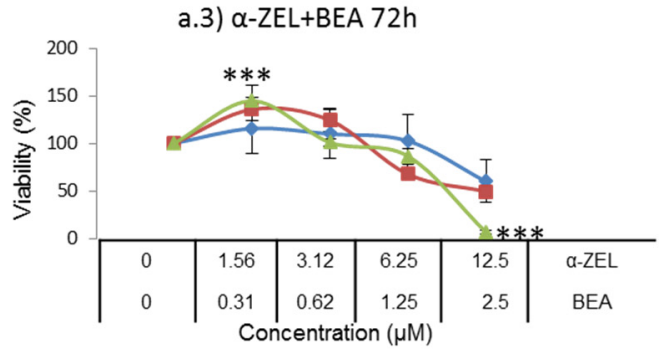
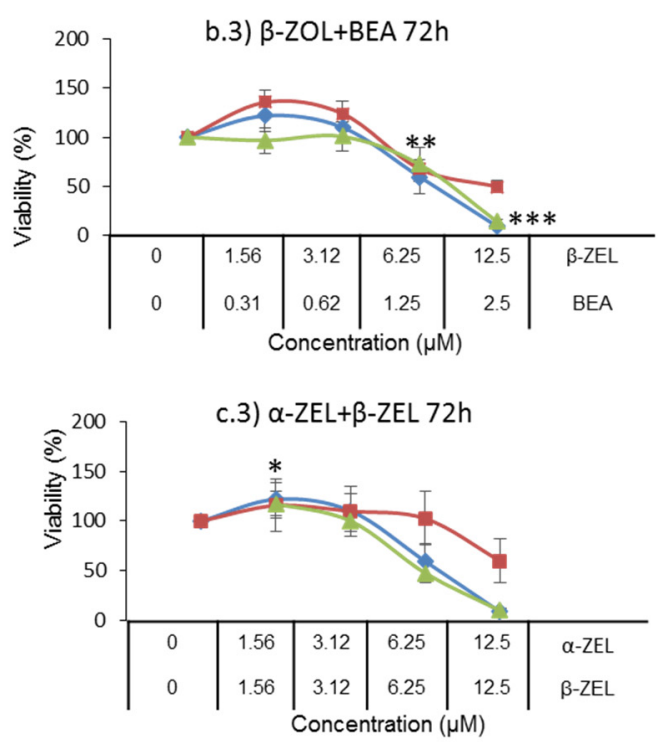

Figure 2. Cytotoxicity of the mycotoxin combinations of $\alpha$-ZEL + BEA (5:1) (a), $\beta$-ZEL + BEA (5:1) (b), and $\alpha$-ZEL + $\beta$-ZEL (1:1) (c) at 24 h (a.1, b.1, and c.1), 48 h (a.2, b.2, and c.2) and $72 \mathrm{~h}\left(\mathrm{a} .3, \mathrm{~b} .3\right.$, and c.3). All values are the results of three independent experiments with eight replicates and are expressed as mean $\pm \mathrm{SD} ; p \leq 0.05\left({ }^{*}\right)$, $\left.\left.p \leq 0.01{ }^{* *}\right), p \leq 0.001{ }^{* * *}\right)$. 


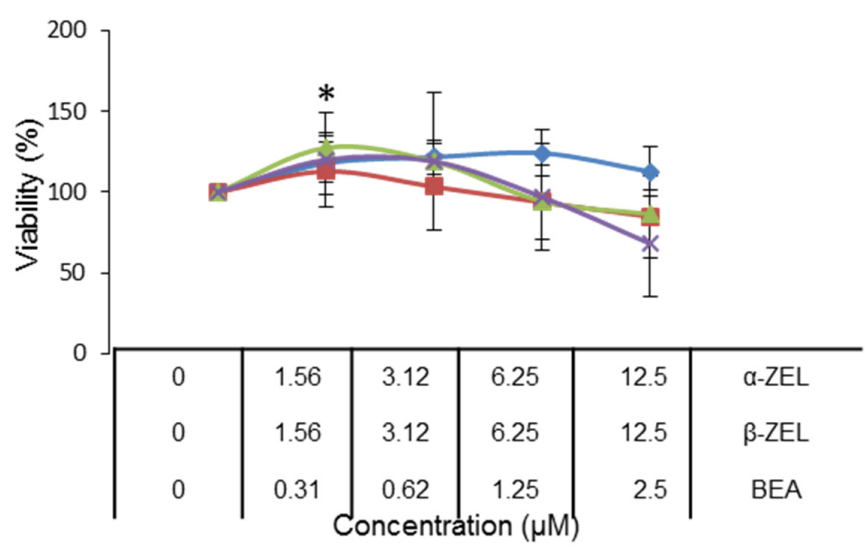

(a)

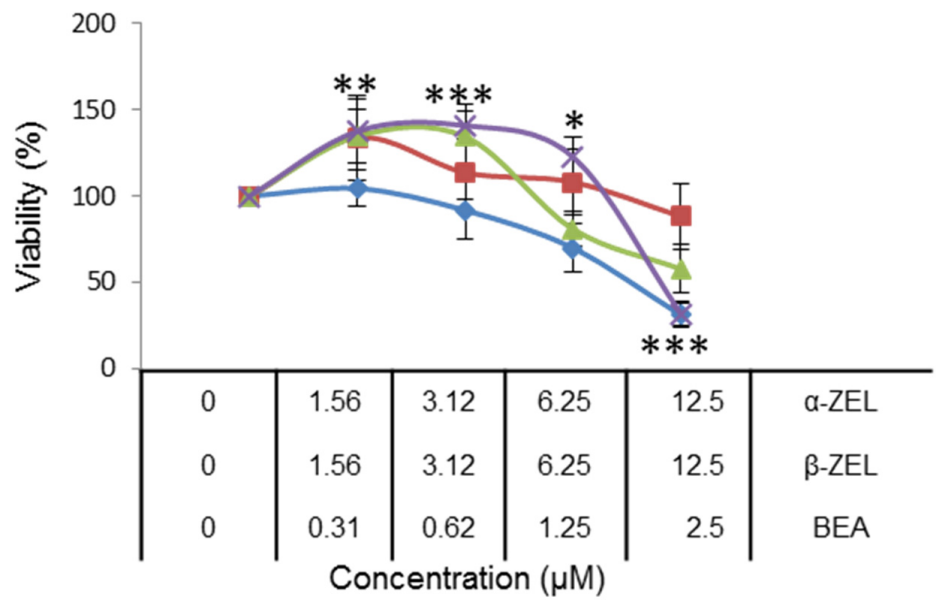

(b)

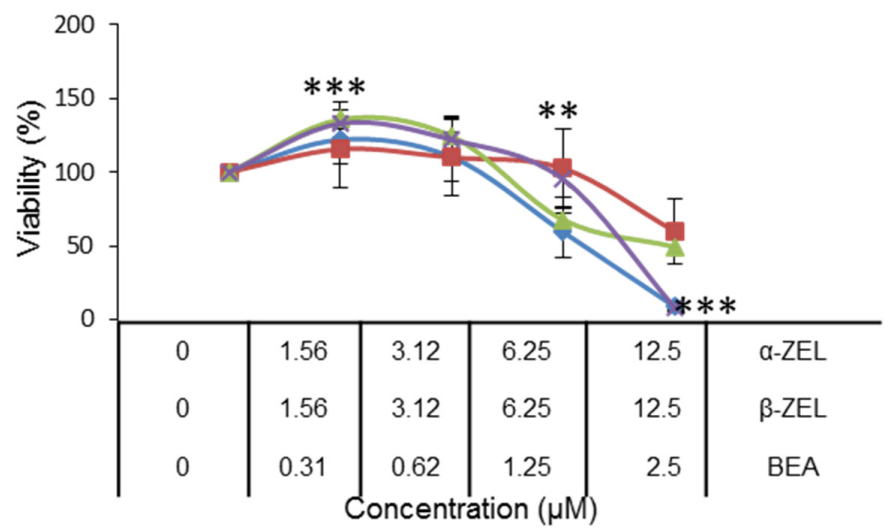

(c)

Figure 3. Cytotoxicity of the mycotoxin combination of $\alpha$-ZEL $+\beta$-ZEL + BEA (5:5:1) at $24 \mathrm{~h}$ (a), $48 \mathrm{~h},(\mathrm{~b})$ and $72 \mathrm{~h}$ (c). All values are the results of three independent experiments with eight replicates and are expressed as mean \pm SD; $\left.p \leq 0.05\left({ }^{*}\right), p \leq 0.01\left(^{* *}\right), p \leq 0.001{ }^{(* *}\right)$. BEA: line and square; $\beta$-ZEL: line and diamond; $\alpha$-ZEL: line and triangle; Mixture: line and $\times$. 
The $\alpha$-ZEL + BEA combination at the highest concentration induced a decrease in cell proliferation at $24 \mathrm{~h}$ of exposure (Figure 2a) of 35\% with respect to the effect $\alpha$-ZEL tested individually and of $37 \%$ with respect to the effect BEA. After $48 \mathrm{~h}$ of exposure, the decrease in cell proliferation was $67 \%$ with respect to that measured for $\alpha$-ZEL and 36\% with respect to that measured for BEA. After $72 \mathrm{~h}$ of exposure, the viability decreased $53 \%$ with respect to $\alpha$-ZEL and $43 \%$ with respect to BEA. After $24 \mathrm{~h}$ of exposure, the $\beta$-ZEL + BEA combination (Figure $2 b$ ) decreased cell proliferation by about $55 \%$ and $29 \%$ at the highest concentration with respect to $\beta$-ZEL and BEA tested individually, respectively. After $48 \mathrm{~h}$ of exposure, the highest concentration of the combination reduced cell proliferation by $11 \%$ with respect to BEA tested individually. Also, at $72 \mathrm{~h}$ of exposure, the combination decreased cell proliferation by approximately $36 \%$ with respect to BEA individually tested. Such effect was not noticed after 48 and $72 \mathrm{~h}$ with respect to b-ZEL. In Figure $2 \mathrm{c}$, the $\alpha$-ZEL $+\beta$-ZEL combination after $24 \mathrm{~h}$ of exposure showed $17 \%$ of decrease in cell proliferation compared to $\beta$-ZEL individually assayed. After 48 and $72 \mathrm{~h}$ of exposure, the highest concentration of the combination reduced cell proliferation by $60 \%$ and $50 \%$, respectively, compared to $\alpha$-ZEL tested alone, whereas, this did not happen with respect to $\beta$-ZEL after 48 and $72 \mathrm{~h}$ of exposure. Figure 3 shows the dose-response curves for the tertiary combination of $\alpha$-ZEL, $\beta$-ZEL, and BEA at 24,48 , and $72 \mathrm{~h}$ of exposure in SH-SY5Y cells. At $24 \mathrm{~h}$ of exposure, cell proliferation decreased by $16 \%, 44 \%$, and $18 \%$ compared to cells exposed to $\alpha$-ZEL, $\beta$-ZEL, and BEA alone. After 48 and $72 \mathrm{~h}$ of exposure, a significant reduction in cell proliferation, corresponding to $57 \%$ and $51 \%$, was observed with respect to $\alpha$-ZEL alone, and a reduction of $26 \%$ and $41 \%$ was observed with respect to BEA alone, while such effect was not observed with respect to $\beta$-ZEL alone.

The isobologram analysis was used to determine the type of interaction between $\alpha$-ZEL, $\beta$-ZEL, and BEA. The values of the parameters $D m, m$, and $r$ of the double and triple combinations, as well as of the mean combination index $(\mathrm{CI})$ are shown in Table 2 . The $\mathrm{IC}_{50}, \mathrm{IC}_{75}$, and $\mathrm{IC}_{90}$ are the doses required to inhibit proliferation at $25 \%, 50 \%, 75 \%$, and $90 \%$, respectively. These CI values were calculated automatically by the computer software CalcuSyn. The CI fractional effect ( $f a$ ) curves for $\alpha$-ZEL, $\beta$-ZEL, and BEA combinations in SH-SY5Y cells are shown in Figure 4. Synergism for all concentration of the $\alpha$-ZEL + BEA (5:1) mixture after 24 and $48 \mathrm{~h}$ of exposure was demonstrated; however, after $72 \mathrm{~h}$ of exposure, an additive effect for the $\alpha$-ZEL + BEA combination was observed (Figure 4a, Table 2). The $\beta$-ZEL + BEA (5:1) mixture showed synergism after $24 \mathrm{~h}$ of exposure; however, after 48 and $72 \mathrm{~h}$ it showed antagonism at high concentrations and moderate synergism at low concentrations (Figure $4 b$, Table 2). The mixture of $\alpha$-ZEL $+\beta$-ZEL showed antagonism after $24 \mathrm{~h}$ of exposure at all concentrations assayed but at 48 and $72 \mathrm{~h}$, it showed antagonism at high concentration and a moderate synergism at low concentration (Figure 4c, Table 2). The tertiary mixture, after $24 \mathrm{~h}$ of exposure, showed antagonism at high concentration and synergism at low concentration, while after $48 \mathrm{~h}$, it showed synergism and after $72 \mathrm{~h}$, antagonism at all concentrations assayed (Figure $4 \mathrm{~d}$, Table 2).

Cytotoxicity after $24 \mathrm{~h}$ of incubation decreased in this order: $\alpha$-ZEL + BEA $>\beta$-ZEL + BEA $>$ $\alpha$-ZEL $+\beta$-ZEL + BEA $>\alpha$-ZEL $+\beta$-ZEL. After 48 and 72 h of incubation, the ranking was $\alpha$-ZEL + BEA $>\beta$-ZEL + BEA $>\alpha$-ZEL $+\beta$-ZEL $>\alpha$-ZEL $+\beta$-ZEL + BEA.

\section{2. $\alpha$-ZEL, $\beta$-ZEL, and BEA Present in Cell Medium after Treatment in Binary and Tertiary Combination}

The medium of SH-SY5Y cells containing $\alpha$-ZEL, $\beta$-ZEL, and BEA after treatments (individual and combined after 24,48 , and $72 \mathrm{~h}$ ) was collected from each well. The amount of each mycotoxin remaining in the medium was calculated as a percentage with respect to the respective amount used in the exposure assays. In this sense, we determined whether the amounts were above or below $50 \%$ of those used for treatment (Figure 5). In individual exposures, the amounts of BEA and $\beta$-ZEL in the medium were below $50 \%$ at 48 and $72 \mathrm{~h}$ (Figure $5 \mathrm{~b}, \mathrm{c}$ ), while, at $24 \mathrm{~h}$, their concentrations tended to be higher and $>50 \%$ for both mycotoxins. For $\alpha$-ZEL, the concentration in the medium was maintained above $50 \%$ at all times studied (Figure $5 \mathrm{a}$ ). This evidenced that a lower amount of $\alpha$-ZEL exerted the 
examined effect compared to the amount necessary for BEA and $\beta$-ZEL, as higher amounts of $\alpha$-ZEL were detectable in the medium at all times and concentrations.

In the binary combination $\alpha$-ZEL + BEA (5:1), the amounts of each mycotoxin after 24 and $48 \mathrm{~h}$ were below $50 \%$ (Figure 5d.1,d.2), although the amount of BEA was higher than that of $\alpha$-ZEL once the concentration assayed overpassed $0.62 \mu \mathrm{M}$ for BEA and $3.12 \mu \mathrm{M}$ for $\alpha$-ZEL, revealing that the effects exerted by this mixture in neuroblastoma cells depended on both mycotoxins and were due more to $\alpha$-ZEL than to BEA. This tendency at $72 \mathrm{~h}$ was more accentuated, as the amount of BEA in the medium was above $50 \%$ for all concentrations, while that of $\alpha$-ZEL was below $50 \%$ (Figure $5 \mathrm{~d} .3$ ).

Also, for the combination $\beta$-ZEL + BEA (5:1), the mycotoxin's percentage remaining in the media was the same as that found for $\alpha$-ZEL + BEA; however, $\beta$-ZEL was detected in higher amount than BEA in all scenarios, revealing that the effect of this mixture and was due more to BEA than to $\beta$-ZEL (Supplementary Figure S1A). On the other hand, for the binary combination of ZEN metabolites, $\alpha$-ZEL $+\beta$-ZEL (1:1), the amounts of mycotoxins recovered were below $50 \%$, and slightly superior for $\alpha$-ZEL than for $\beta$-ZEL. This revealed that both mycotoxins contributed to the effect of this mixture in SH-SY5Y cell line (Supplementary Figure S1B). For the tertiary combination $(\alpha-Z E L+\beta$-ZEL + BEA, (5:5:1)), the mycotoxins' percentages detected were also below $50 \%$ of the administered concentration, and this percentage was higher for higher concentrations administered and lower time of exposure (Figure 5e). This revealed that high amounts of $\alpha$-ZEL and $\beta$-ZEL accessed the neuroblastoma cells, and the effect was due more to $\beta$-ZEL at 48 and $72 \mathrm{~h}$, according to the results in Figures 3 and 5.

Table 2. The parameters $D m, m$, and $r$ are the antilog of $\mathrm{x}$-intercept, the slope, and the linear correlation of the median-effect plot, which means the shape of the dose-effect curve, the potency $\left(\mathrm{IC}_{50}\right)$, and the conformity of the data to the mass action law, respectively [30,31]. Dm and $m$ values are used for calculating the combination index (CI) value (CI $<1,=1$, and $>1$ indicate synergism (Syn), additive (Add) effect, and antagonism (Ant), respectively. $\mathrm{IC}_{50}, \mathrm{IC}_{75}$, and $\mathrm{IC}_{90}$ are the doses required to inhibit proliferation at $50 \%, 75 \%$, and $90 \%$, respectively. CalcuSyn software automatically provided theses values.

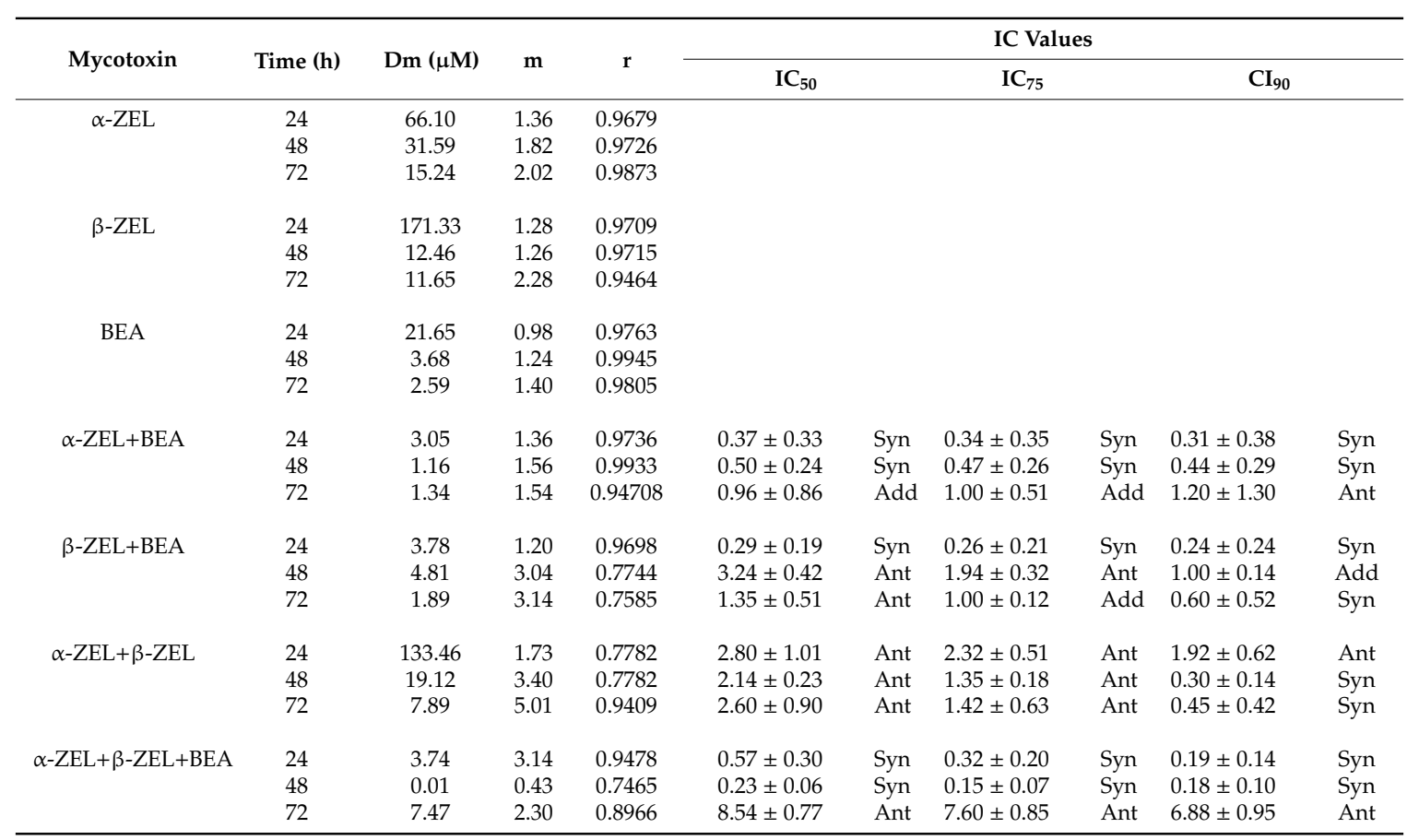



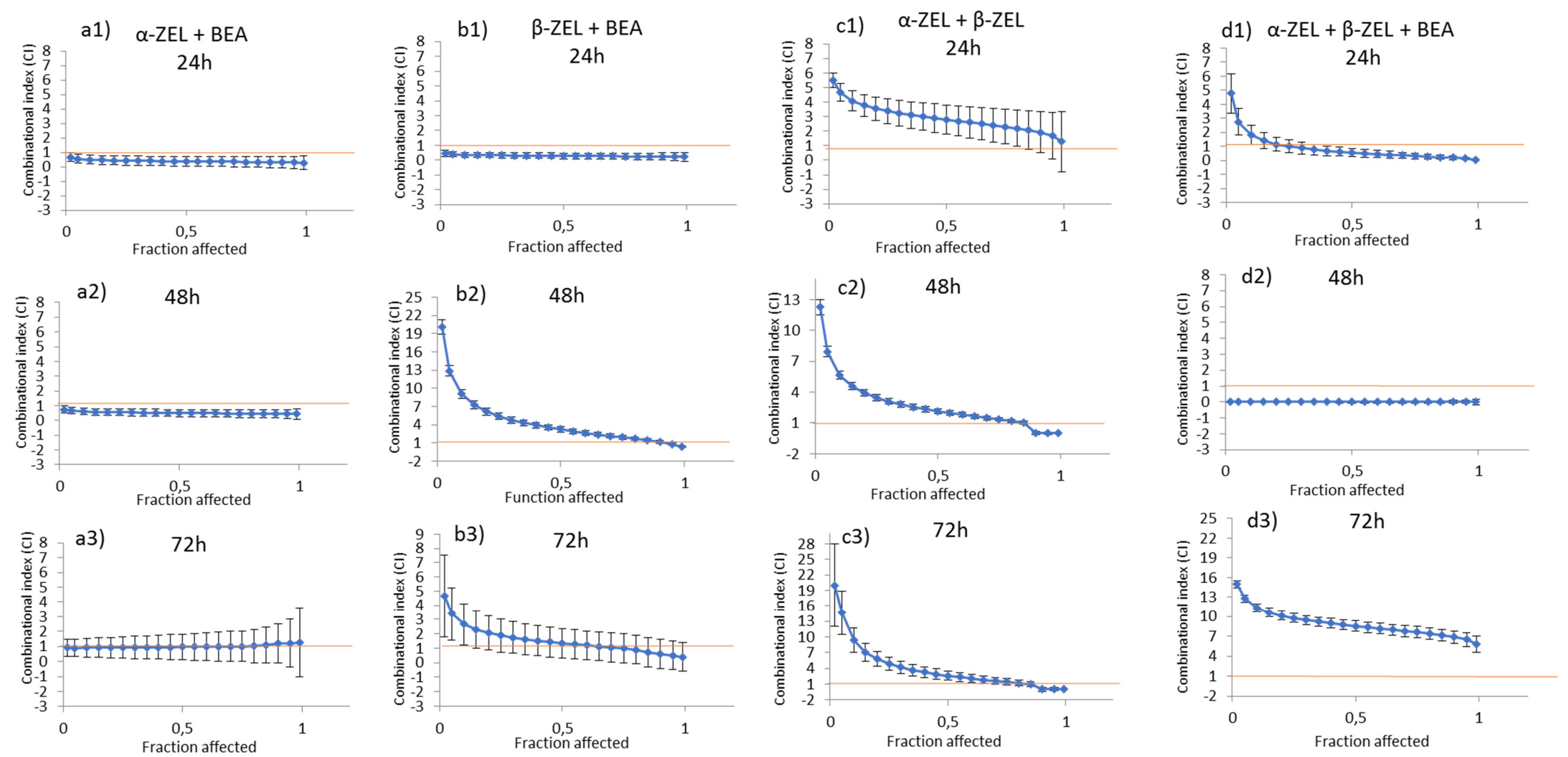

Figure 4. CI vs. fractional effect curve, as described by Chou and Talalay, for SH-SY5Y cells exposed to $\alpha$-ZEL, $\beta$-ZEL, and BEA in binary and tertiary combinations. Each point represents the $\mathrm{CI} \pm \mathrm{SD}$ at a fractional effect as determined in our experiments. The line $(\mathrm{CI}=1)$ indicates additivity, the area under this line indicates synergism, and the area above the line indicates antagonism. SH-SY5Y cells were exposed for 24, 48, and $72 \mathrm{~h}$ to $\alpha$-ZEL + BEA and $\beta$-ZEL + BEA at a molar ratio of 5:1 (equimolar proportion), to $\alpha$-ZEL + $\beta$-ZEL at a molar ratio of 1:1, and to $\alpha$-ZEL $+\beta-Z E L+$ BEA at a molar ratio of 5:5:1. 
a)

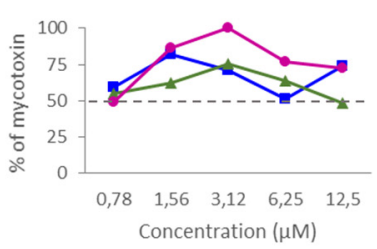

d)

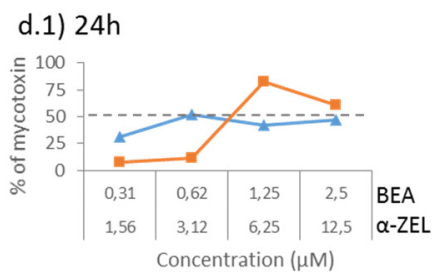

e)

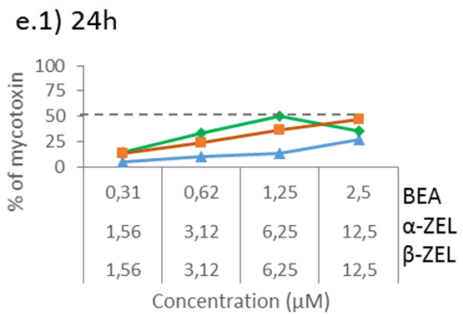

b)

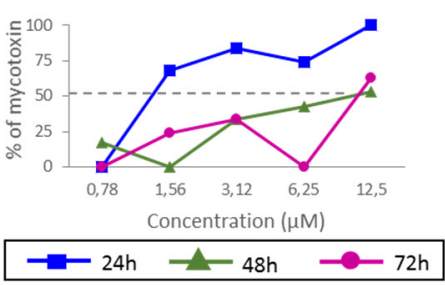

d.2) $48 \mathrm{~h}$
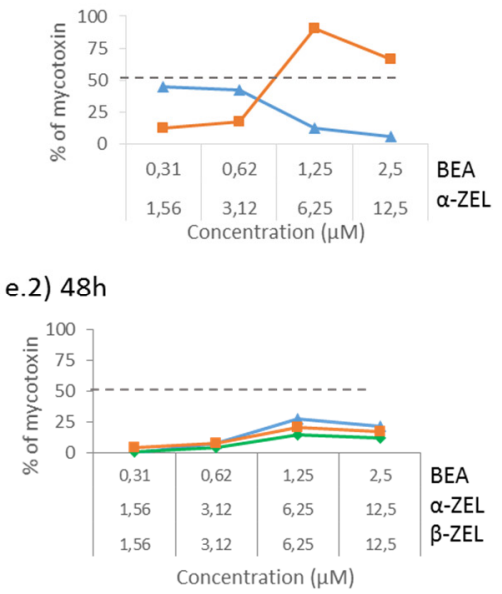

c)

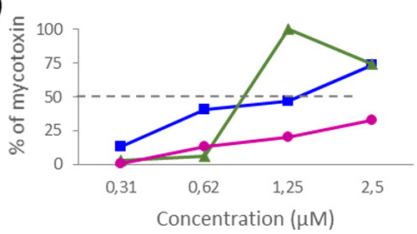

d.3) $72 \mathrm{~h}$
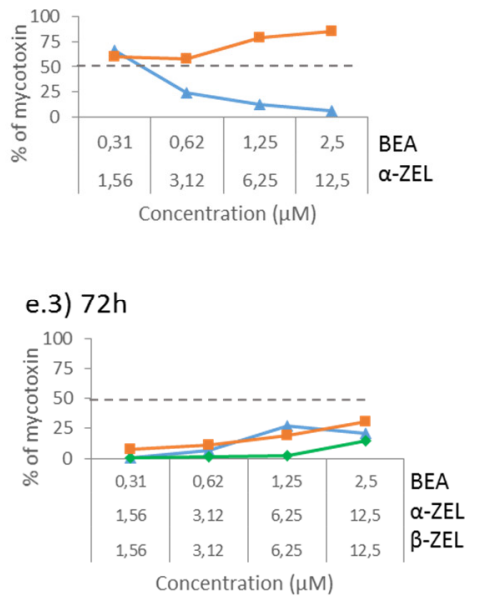

$\neg \alpha-Z E L \quad-\beta-Z E L \quad \rightarrow-B E A$

Figure 5. Percentage of $\alpha$-ZEL, $\beta$-ZEL, and BEA remaining in the medium of SH-SY5Y cells after treatment for 24,48 , and $72 \mathrm{~h}$ at different concentrations individually or in combination by LC-ESI-qTOF-MS. (a) $\alpha$-ZEL; (b) $\beta$-ZEL; (c) BEA; (d) $\alpha$-ZEL + BEA and (e) $\alpha$-ZEL + $\beta$-ZEL + BEA.

\section{Discussion}

Several studies have discussed the cytotoxic and an anti-proliferative effect of ZEN mycotoxin and its metabolites in various cell lines, such as Caco-2 [11], HepG2 cells [13], CHO-K1 cells [32], and SH-SY5Y [6], and hose of BEA mycotoxin in Caco [14], CHO-K1 [19], and Hep G2 cells [17]. However, there are no reports on the effect of ZEN metabolites and BEA in neuronal cells. In the present study, we proved the toxicity of ZEN metabolites ( $\alpha$-ZEL and $\beta$-ZEL) and BEA in human neuroblastoma SH-SY5Y cells in relation to exposure time, mycotoxin concentration, and mixture of mycotoxins.

According to the $\mathrm{IC}_{50}$ values of single mycotoxins, $\beta$-ZEL was the most cytotoxic mycotoxin compared to the other mycotoxins assayed individually, which is in accordance with Marin et al. (2019) [33] who studied the cytotoxicity of ZEN and its metabolites in HepG2 cells, individually and in double combinations. On the contrary, Tatay et al. (2014) [32] demonstrated that $\alpha$-ZEL was the most cytotoxic among three mycotoxins tested ( $\alpha$-ZEL, $\beta$-ZEL, and ZEN) in CHO-K1 cells. Regarding to double combinations, it was revealed that presence of two mycotoxins increased the cytotoxic potential in SH-SY5Y cells, as shown by the lower IC $_{50}$ values. According to Figure $2 \mathrm{a}$, IC50 for $\alpha$-ZEL and BEA was not reached in individual treatment however, binary combination $\alpha$-ZEL + BEA (5:1) inhibited cell proliferation from up to 50 to $90 \%$ for all times studied. For the $\beta$-ZEL + BEA (5:1) binary combination, as it can be observed in Figure $2 \mathrm{~b}$, the $\mathrm{IC}_{50}$ values at 48 and $72 \mathrm{~h}$ were lower than that of $\beta$-ZEL. This was also observed when $\beta$-ZEL was combined with $\alpha$-ZEL, for which combination $\left(\alpha\right.$-ZEL $+\beta$-ZEL (1:1)), the IC C0 $_{50}$ value was the same as that found for $\beta$-ZEL alone. This result was not achieved by Tatay et al. (2014) [31] in CHO-K1 cells, although the mycotoxin concentrations studied in binary assays in that work were two times higher than the concentrations assayed in our study. The proliferation of CHO-K1 cells treated with the $\alpha$-ZEL $+\beta$-ZEL mixture at the highest concentration 
decreased only by $20 \%$ with respect to the values found when each mycotoxin was tested alone. In addition, in that study, the $\mathrm{IC}_{50}$ value was never reached for binary mixtures, whereas in our study in SH-SY5Y cells, after 48 and $72 \mathrm{~h}$, the $\alpha$-ZEL $+\beta$-ZEL combination inhibited cell proliferation up to $70 \%$ and $90 \%$, respectively (Figure $2 c)$. For the triple combination ( $\alpha$-ZEL + $\beta$-ZEL + BEA, (5:5:1)), cell proliferation inhibition was lower than when $\beta$-ZEL was assayed individually, and the same result was found for $\beta$-ZEL + BEA after 48 and $72 \mathrm{~h}$ and for $\alpha$-ZEL $+\beta$-ZEL after $48 \mathrm{~h}$ in SH-SY5Y cells. This is in contrast with the results obtained for the tertiary combination of $\alpha$-ZEL $+\beta-Z E L+Z E N$ in CHO-K1 cells, as this combination was more cytotoxic than each mycotoxin tested alone [30].

As the co-occurrence of mycotoxins in food and feed is very common, some studies evaluated the toxicity and cytotoxicity of several mycotoxins, both individually and in combination, in different cell lines, using the isobologram model. In these experiments, HepG2 cells were exposed to ochratoxin A (OTA) and BEA [16], to double and triple combinations of alternariol, 3-acetyl-deoxynivalenol, and 15-acetyl-deoxynivalenol [28], and to combinations of ZEN and OTA or $\alpha$-ZEL (tested also individually) [33], $\mathrm{CHO}-\mathrm{K} 1$ cells in vitro were used to examine the interactions between the mycotoxins beauvericin, deoxynivalenol (DON), and T-2 toxin [26] as well as the combination of BEA, patulin, and ZEN [17], whereas Caco-2 cells were exposed to DON, ZEN, and Aflatoxin B1 [34]. It is important to understand whether the interaction between mycotoxins shows synergism, additive effects, and/or antagonism concerning cell viability.

In SH-SY5Y cells, almost all the combinations tested reduced cell viability more than the individual mycotoxins, except the $\beta$-ZEL + BEA (5:1), $\alpha$-ZEL $+\beta$-ZEL (1:1), and $\alpha$-ZEL $+\beta$-ZEL + BEA (5:5:1) combinations, for which the reduction in cell viability was not significantly different from that obtained when $\beta$-ZEL was assayed individually. According to Dong et al. (2010) [5], ZEN is degraded more efficiently to $\alpha$-ZEL than to $\beta$-ZEL in almost all tissues, whereas it is converted more efficiently to $\beta$-ZEL than to $\alpha$-ZEL in liver and lungs. Some studies demonstrated that $\beta$-ZEL is more cytotoxic than $\alpha$-ZEL $[31,35,36]$, whereas other studies found that $\alpha$-ZEL is more cytotoxic $[30,35]$. Hence, there is a necessity to clarify the cytotoxicity of these two mycotoxins with studies of the toxicity mechanisms involved.

The $\mathrm{IC}_{50}$ values obtained by the MTT assay and the amount of mycotoxin detected in the media by LC-ESI-qTOF-MS were determined and translated into percentage values as an attempt to calculate the amount of each mycotoxin involved in the cytotoxic effect and in the type of interaction effect. Hence, the percentage of mycotoxin present in the media was considered in accordance to the $\mathrm{IC}_{50}$ value obtained from the MTT assay (Table 1). The results showed that among the individual mycotoxins assayed, the amount of $\alpha$-ZEL that remained in the culture medium was above $50 \%$ of the administered quantity at all times assayed (Figure 5a). This can be related to the effect in Figure 1a, which shows that the viability was above $100 \%$ for the doses reported in Figure 5 . This can be justified by the chemical structure of this compound, which might impede its access in the cell. Our results suggest that the availability and capacity of the tested mycotoxins to get into cells were greater than those of $\alpha$-ZEL, and as a consequence, the amounts of these mycotoxins detected in the media were lower than that of $\alpha$-ZEL. To notice that the higher the amount of mycotoxin in the medium (at $24 \mathrm{~h}$ ), the higher the cell viability, which might be related to the lower amount of mycotoxin affecting the live cells. On the contrary, BEA seemed to have easier access the cells, as its percentage in the medium was generally below $50 \%$, but cell viability was maintained above $50 \%$ for the doses assayed, indicating the lower potential toxicity of BEA in SH-SY5Y cells compared to ZEN metabolites. In fact, among all three mycotoxins tested, BEA reached the $\mathrm{IC}_{50}$ values after long exposures times (72 h) (Table 1 and Figure $1 \mathrm{c}$ ), highlighting again the mild toxic effect of BEA in SHY-SY5Y cells compared to ZEN metabolites.

According to this and when analyzing combinations, the amounts of ZEN metabolites found in the medium were in most cases below BEA's amounts, indicating easier access of these compounds in SH-SY5Y compared to BEA. In detail, for the $\alpha$-ZEL + BEA combination (Figure 2a), it can be observed that the lower the amount of $\alpha$-ZEL in the medium over time (Figure $5 \mathrm{~d}$ ), the lower the viability of SH-SY5Y cells, in particular at 72h. For triple mixtures, the cytotoxic effect was weaker 
at all times and for all mixtures compared with that of binary combinations; however, the amounts of each mycotoxin detected were all below $50 \%$, and the cytotoxic effect seemed to be bearable for SH-SY5Y cells for doses administered in the first and second mixture but not for those of the third mixture $(6.25+6.26+1.25) \mu \mathrm{M}(\alpha$-ZEL $+\beta$-ZEL + BEA, 5:5:1), specifically at 48 and $72 \mathrm{~h}$. We suggest that cytotoxicity is due to the stimulation of different biochemical mechanisms that, after a certain level of stimulation, cannot be controlled and cause cell death. Therefore, it is necessary to study in detail the mechanisms of action implicated in the cytotoxic effects that occur when several mycotoxins are present in the same food or diet.

\section{Conclusions}

In conclusion, the treatment with $\beta$-ZEL alone presented the highest cytotoxicological potency compared to treatments with the other mycotoxins assayed ( $\alpha$-ZEL and BEA). The main type of interaction detected between mycotoxins for all combinations assayed was synergism. The potential interaction effects between combinations in this study are difficult to explain since $\alpha$-ZEL + BEA for binary and $\alpha$-ZEL $+\beta$-ZEL + BEA for tertiary combination were found more in favor of synergic effect respect to $C I$ value, compared with other combinations, which could be related to the concentration range studied, ratio in each mixture, exposure time assayed and cell line studied. Moreover, among all mycotoxins assayed, $\alpha$-ZEL appeared to remain in the culture medium and was less able to get into SH-SY5Y cells compared to BEA and $\beta$-ZEL. In combinations, such effect was observed for BEA reaching the highest in $\alpha$-ZEL + BEA.

\section{Materials and Methods}

\subsection{Reagents}

The reagent-grade chemicals and cell culture components used, Dulbecco's Modified Eagle's Medium- F12 (DMEM/F-12), fetal bovine serum (FBS), and phosphate-buffered saline (PBS) were supplied by Thermofisher, Gibco ${ }^{\mathrm{TM}}$ (Paisley, UK). Methanol (MeOH, HPLC LS/MS grade), was obtained from VWR International (Fontenay-sous-Bois, France). Dimethyl sulfoxide was obtained from Fisher Scientific Co, Fisher BioReagnts TM (Geel, Belgium). The compound (3-(4,5-dimethylthiazol-2-yl)-2,5diphenyltetrazolium bromide) (MTT) for the MTT assay, penicillin, streptomycin, and Trypsin-EDTA were purchased from SigmaAldrich (St. Louis, MO, USA). Deionized water $(<18, \mathrm{M} \Omega \mathrm{cm}$ resistivity) was obtained in the laboratory using a Milli-QSP ${ }^{\circledR}$ Reagent Water System (Millipore, Beadford, MA, USA). Standard BEA (MW: $783.95 \mathrm{~g} / \mathrm{mol}$ ), $\alpha$-ZEL, and $\beta$-ZEL (MW: $320.38 \mathrm{~g} / \mathrm{mol}$ ) were purchased from SigmaAldrich (St. Louis Mo. USA) (Figure 6). Stock solutions of mycotoxins were prepared in $\mathrm{MeOH}$ $\left(\alpha\right.$-ZEL and $\beta$-ZEL) and DMSO (BEA) and maintained at $-20{ }^{\circ} \mathrm{C}$ in the dark. The final concentration of either methanol or DMSO in the medium was $\leq 1 \%(\mathrm{v} / \mathrm{v})$ as previously established. All other reagents were of standard laboratory grade.

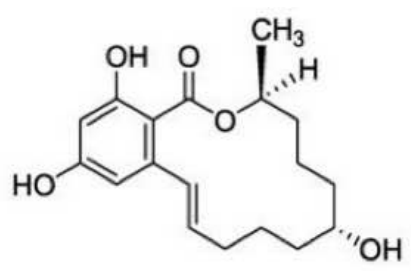

(a)

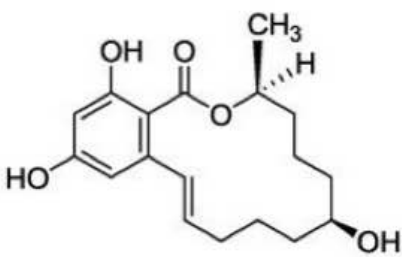

(b)

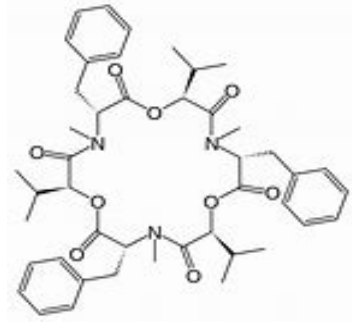

(c)

Figure 6. Chemical structures of the mycotoxins (a) $\alpha$-ZEL, (b) $\beta$-ZEL, and (c) BEA. 


\subsection{Cell Culture}

The human neuroblastoma cell line SH-SY5Y was obtained from the American Type Culture Collection (ATCC, Manassas, VA, USA) and cultured in Dulbecco's Modified Eagle's Medium/F12 (DMEM/F-12), supplemented with $10 \% \mathrm{FBS}, 100 \mathrm{U} / \mathrm{mL}$ penicillin, and $100 \mathrm{mg} / \mathrm{mL}$ streptomycin. The cells were sub-cultivated after trypsinization once or twice a week and suspended in complete medium in a 1:3 split ratio. The cells were maintained as monolayers in $150 \mathrm{~cm}^{2}$ cell culture flasks with filter screw caps (TPP, Trasadingen, Switzerland). Cell cultures were incubated at $37^{\circ} \mathrm{C}, 5 \% \mathrm{CO}_{2}$ atmosphere.

\subsection{Mycotoxin Exposure}

Concentration of the mycotoxins and exposure time are two factors that were considered to in this study. The cells were exposed to $\alpha$-ZEL, $\beta$-ZEL, and BEA mycotoxins individually for 24,48 , and $72 \mathrm{~h}$ at a concentration in the ranges of 0.39 to $100 \mu \mathrm{M}$ for $\alpha$-ZEL and $\beta$-ZEL and 0.009 to $25 \mu \mathrm{M}$ for BEA, all with 1:2 dilution (Table 3). Also, the mycotoxins were assayed in combination in the following mixtures: $\alpha$-ZEL + BEA, $\beta$-ZEL + BEA, $\alpha$-ZEL $+\beta$-ZEL, and $\alpha$-ZEL $+\beta$-ZEL + BEA at three exposure times 24,48 , and $72 \mathrm{~h}$. The concentrations ranged from 1.87 to $25 \mu \mathrm{M}$ for the binary combinations were studied and from 3.43 to $27.5 \mu \mathrm{M}$ for the tertiary combination, including four dilutions of each mycotoxin: BEA $(0.31,0.62,1.25$, and $2.5 \mu \mathrm{M}), \alpha$-ZEL and $\beta$-ZEL $(1.56,3.12,6.25$ and $12.5 \mu \mathrm{M})$ (Table 3). The dilution ratios of the concentrations for the binary combinations were 5:1 for $\alpha$-ZEL + BEA and $\beta$-ZEL + BEA, 1:1 for $\alpha$-ZEL $+\beta$-ZEL, and 5:5:1 for the tertiary combination ( $\beta$-ZEL $+\alpha$-ZEL + BEA) (Table 3).

Table 3. Concentration range $(\mu \mathrm{M})$ of mycotoxins studied individually and in combinations. The dilution ratios were 5:1 for the combinations $\alpha$-ZEL + BEA and $\beta$-ZEL + BEA, 1:1 for $\alpha$-ZEL + $\beta$-ZEL, and 5:5:1 for $\alpha$-ZEL $+\beta$-ZEL + BEA.

\begin{tabular}{ll}
\hline Combination Tested & Concentration Range $(\mu \mathbf{M})$ \\
\hline$\alpha-Z E L$ & $(0.39-00)$ \\
$\beta-Z E L$ & $(0.39-100)$ \\
BEA & $(0.009-25)$ \\
$\alpha-Z E L+$ BEA & $(1.56-2.5)+(0.31-2.5)$ \\
$\beta-Z E L+$ BEA & $(1.56-2.5)+(0.31-2.5)$ \\
$\alpha-Z E L+\beta-Z E L$ & $(1.56-12.5)+(1.56-12.5)$ \\
$\alpha-Z E L+\beta-Z E L+B E A$ & $(1.56-12.5)+(1.56-12.5)+(0.31-2.5)$ \\
\hline
\end{tabular}

\subsection{MTT Assay}

Cytotoxicity was examined by the MTT assay, performed as described by Ruiz et al. (2006) [37], with few modifications. The assay consists in measuring the viability of cells by determining the reduction of the yellow soluble tetrazolium salt only in cells that are metabolically active via a mitochondrial reaction to an insoluble purple formazan crystal. Cells were seeded in 96-well culture plates at $2 \times 96$ cells/well and allowed to adhere for $18-24 \mathrm{~h}$ before mycotoxin additions. Serial dilutions of $\alpha$-ZEL, $\beta$-ZEL, and BEA at 1:2 dilutions were prepared with supplemented medium and added to the respective plates (Table 3). Culture medium without mycotoxins and with $1 \% \mathrm{MeOH}$ or DMSO was used as a control. After treatment, the medium was removed, and each well received $200 \mu \mathrm{L}$ of fresh medium containing $50 \mu \mathrm{L}$ of MTT solution $(5 \mathrm{mg} / \mathrm{mL}$; MTT powder dissolved in phosphate-buffered saline). After an incubation time of $4 \mathrm{~h}$ at $37^{\circ} \mathrm{C}$ in the darkness, the MTT-containing medium was removed, and $200 \mu \mathrm{L}$ of DMSO and $25 \mu \mathrm{L}$ of Sorensen's solution were added to each well before reading the optical density at $620 \mathrm{~nm}$ with the ELISA plate reader Multiskan EX (Thermo Scientific, MA, USA). Each mycotoxin combination plus a control were tested in three independent experiments. Mean inhibition concentration $\left(\mathrm{IC}_{50}\right)$ values were calculated from full dose-response curves. 


\subsection{Experimental Design and Combination Index}

The isobologram analysis (Chou-Talalay model) was used to determine the type of interaction (synergism, additive effect, and antagonism) that occurred when the mycotoxins studied were in combination. This model allows characterizing the interactions induced by combinations of mycotoxins in different cell lines and with different mycotoxins but it does not allow the elucidation of the mechanisms by which these types of interaction are produced. The median effect/combination index (CI) isobologram equation by Chou (2006) [31] and Chou and Talalay (1984) [30] permitted analyzing drug combination effects. The isobologram analysis involves plotting the dose-effect curves for each compound and its combinations in multiple diluted concentrations. Parameters such as Dm (median effect dose), $f a$ (fraction affected by concentration), and $m$ (coefficient signifying the shape of the dose-effect relationship) are relevant in the equation [30]. Therefore, the method considers both potency $(D m)$ and shape $(m)$ parameters.

Chou and Talalay (1984) [30] introduced the term combination index (CI). CI values $<1,=1$, and $>1$ indicate synergism, additive effects, and antagonism of the combination, respectively. CalcuSyn software version 2.1. (Biosoft, Cambridge, UK, 1996-2007) was used to study the types of interactions assessed by the isobologram analysis. The $\mathrm{IC}_{25}, \mathrm{IC}_{50}, \mathrm{IC}_{75}$, and $\mathrm{IC}_{90}$ are the doses required to produce toxicity at $25 \%, 50 \%, 75 \%$, and $90 \%$, respectively.

\subsection{Extraction of $\alpha$-ZEL, $\beta$-ZEL, and BEA from the Culture Media}

To determine the intracellular accumulation of the mycotoxins studied, an extraction procedure of the culture media was carried out following the method described by Juan-García et al. (2015 and 2016) [27,28], with several modifications. Briefly, $0.8 \mathrm{~mL}$ of culture medium was collected and transferred into a polypropylene tube, $1.5 \mathrm{~mL}$ of ethyl acetate was added, and the mixture was shaken for $2 \mathrm{~min}$ with an Ultra-Turrax Ika T18 basic (Staufen, Germany). Afterwards, the mixture as sonicated in an ultrasound cleaning bath (VWR, USC1700TH) for $10 \mathrm{~min}$. Finally, the mixture was centrifuged at $\sim 5600 \times \mathrm{g}$ for $5 \mathrm{~min}$ at $22{ }^{\circ} \mathrm{C}$ (Centrifuge 5810R, Eppendorf, Germany). The supernatant phase was collected. The liquid-liquid extraction process was repeated three times. Finally, the total volume obtained (approx. $4.5 \mathrm{~mL}$ ) was evaporated to dryness at $45^{\circ} \mathrm{C}$ in an $\mathrm{N} 2$ stream with a TurboVap-LV (Zymark, Allschwil, Switzerland) and then re-dissolved in $0.25 \mathrm{~mL}$ of a mixture of methanol and water (70:30, $\mathrm{v} / \mathrm{v}$ ) by vortexing vigorously (15 s), before being transferred into a vial for LC-ESI-qTOF-MS injection.

\subsection{Determination of BEA, $\beta$-ZEL, and $\alpha$-ZEL by LC-ESI-qTOF-MS}

The analysis was performed using an LC-ESI-qTOF-MS system, consisting of an LC Agilent 1200-LC system (Agilent Technologies, Palo Alto, CA, USA) equipped with a vacuum degasser, an autosampler, and a binary pump. The columns were a Gemini NX-C18 column $(150 \times 2 \mathrm{~mm}$, i.d. $3 \mu \mathrm{m}$, Phenomenex, Torrance, California) and a guard column C18 $(4 \times 2 \mathrm{~mm}$, i.d. $3 \mu \mathrm{M})$.

Mobile phases consisted of milli-Q water with $0.1 \%$ of formic acid as solvent system A and acetonitrile and $0.1 \%$ of formic acid as solvent system $\mathrm{B}$, with the following gradient elution: 3 min, $70 \%$ B; in 2 min $70-80 \%$ B; in 1 min get $90 \%$ of B, maintained 4 min; $90-100 \%$ B 4 min and maintained $2 \mathrm{~min}$; in $2 \mathrm{~min}$ decrease to $50 \% \mathrm{~B}$; in $2 \mathrm{~min} 90 \% \mathrm{~B}$, maintained $2 \mathrm{~min}$. The flow rate used was $0.250 \mathrm{~mL}$ $\min ^{-1}$, and the total run time was $22 \mathrm{~min}$. The sample volume injected was $20 \mu \mathrm{L}$.

MS analysis was carried out using a 6540 Agilent Ultra- High-Definition Accurate-Mass q-TOF-MS, equipped with an Agilent Dual Jet Stream electrospray ionization (Dual AJS ESI) interface in negative and positive ionization modes. Operation conditions were as follows: sheath gas temperature $350{ }^{\circ} \mathrm{C}$ at a flow rate of $8 \mathrm{~L} / \mathrm{min}$, capillary voltage $3500 \mathrm{~V}$, nebulizer pressure $45 \mathrm{psig}$, drying gas $10 \mathrm{~L} / \mathrm{min}$, gas temperature $300^{\circ} \mathrm{C}$, skimmer voltage $65 \mathrm{~V}$, octopole RF peak $750 \mathrm{~V}$, and fragmentor voltage $130 \mathrm{~V}$. Analyses were performed using AutoMS/MS mode with fixed collision energy (10, 20 and 30) and in mass range of $50-1700 \mathrm{~m} / \mathrm{z}$. Acquisition rate was 3 spectra/second. Acquisition data were processed with Agilent MassHunter Workstation software. 


\subsection{Statistical Analysis}

Statistical analysis of data was carried out using IBM SPSS Statistic version 23.0 (SPSS, Chicago, Il, USA) statistical software package. Data are expressed as mean \pm SD of three independent experiments. The statistical analysis of the results was performed by student's T-test for paired samples. Difference between groups were analyzed statistically with ANOVA followed by the Tukey HDS post-hoc test for multiple comparisons. The level of $p \leq 0.05$ was considered statistically significant.

Supplementary Materials: The following are available online at http://www.mdpi.com/2072-6651/12/4/212/s1, Figure S1. Percentage of $\alpha$-ZEL, $\beta$-ZEL, and BEA remaining in the medium of SH-SY5Y cells after treatment during 24,48 , and $72 \mathrm{~h}$ at different concentrations and combinations by LC-ESI-qTOF-MS. (A) $\beta$-ZEL+ BEA and (B) $\alpha$-ZEL $+\beta$-ZEL.

Author Contributions: Data curation, F.A.; Formal analysis, C.J. and A.J.-G.; Funding acquisition, G.F., C.J., and A.J.-G.; Investigation, F.A., C.J., and A.J.-G.; Methodology, A.J.-G.; Supervision, C.J. and A.J.-G.; Writing-original draft, F.A, C.J. and A.J.-G.; Writing-review \& editing, C.J. and A.J.-G. All authors have read and agreed to the published version of the manuscript.

Funding: This research was supported by the Spanish Ministry of Economy and Competitiveness AGL2016-77610-R and the Generalitat Valenciana GVPROMETEO2018-126.

Conflicts of Interest: The authors declare no conflict of interest.

\section{References}

1. Zain, M.E. Impact of mycotoxins on humans and animals. J. Saudi Chem. Soc. 2011, 15, 129-144. [CrossRef]

2. Mally, A.; Solfrizzo, M.; Degen, G.H. Volume Biomonitoring of the mycotoxin Zearalenone: Current state-of-the art and application to human exposure assessment. Arch. Toxicol. 2016, 90, 1281-1292. [CrossRef] [PubMed]

3. Richard, J.L. Some major mycotoxins and their mycotoxicoses-An overview. Int. J. Food Microbiol. 2007, 119, 3-10. [CrossRef] [PubMed]

4. Hueza, I.M.; Raspantini, P.C.; Raspantini, L.E.; Latorre, A.O.; Górniak, S.L. Zearalenone, an estrogenic mycotoxin, is an immunotoxic compound. Toxins 2014, 6, 1080-1095. [CrossRef]

5. Dong, M.; Tulayakul, P.; Li, J.-Y.; Dong, K.-S.; Manabe, N.; Kumagai, S. Metabolic Conversion of Zearalenone to $\alpha$-Zearalenol by Goat Tissues. J. Vet. Med. Sci. 2010, 72, 307-312. [CrossRef]

6. Venkataramana, M.; Chandra Nayaka, S.; Anand, T.; Rajesh, R.; Aiyaz, M.; Divakara, S.T.; Murali, H.S.; Prakash, H.S.; Lakshmana Rao, P.V. Zearalenone induced toxicity in SHSY-5Y cells: The role of oxidative stress evidenced by N-acetyl cysteine. Food Chem. Toxicol. 2014, 65, 335-342. [CrossRef]

7. Gajecka, M.; Zielonka, L.; Gajecki, M. The effect of low monotonic doses of zearalenone on selected reproductive tissues in pre-pubertal female dogs-a review. Molecules 2015, 20, 20669-20687. [CrossRef]

8. EFSA CONTAM Panel (EFSA Panel on Contaminants in the Food Chain). Scientific opinion on the appropriateness to set a group health-based guidance value for zearalenone and its modified forms. EFSA J. 2016, 14, 4425.

9. Wang, J.J.; Wei, Z.K.; Han, Z.; Liu, Z.Y.; Zhu, X.Y.; Li, X.W.; Wang, K.; Yang, Z.T. Zearalenone Induces Estrogen-Receptor-Independent Neutrophil Extracellular Trap Release in Vitro. J. Agric. Food Chem. 2019, 67, 4588-4594. [CrossRef]

10. El-Makawy, A.; Hassanane, M.S.; Abd Alla, E.S.A.M. Genotoxic evaluation for the estrogenic mycotoxin zearalenone. Reprod. Nutr. Dev 2001, 41, 79-89. [CrossRef]

11. Abid-Essefi, S.; Baudrimont, I.; Hassen, W.; Ouanes, Z.; Mobio, T.A.; Anane, R.; Creppy, E.E.; Bacha, H. DNA fragmentation, apoptosis and cell cycle arrest induced by zearalenone in cultured DOK, Vero and Caco-2 cells: Prevention by Vitamin E. Toxicology 2003, 192, 237-248. [CrossRef]

12. Cai, G.; Pan, S.; Feng, N.; Zou, H.; Gu, J.; Yuan, Y.; Liu, X.; Liu, Z.; Bian, J. Zearalenone inhibits T cell chemotaxis by inhibiting cell adhesion and migration related proteins. Ecotox. Environ. Safe 2019, 175, $263-271$. [CrossRef]

13. Hassen, W.; El Golli, E.; Baudrimont, I.; Mobio, A.T.; Ladjimi, M.M.; Creppy, E.E.; Bacha, H. Cytotoxicity and Hsp70 induction in HepG2 cells in response to zearalenone and cytoprotection by sub-lethal heat shock. Toxicology 2005, 207, 293-301. [CrossRef] [PubMed] 
14. Prosperini, A.; Juan-García, A.; Font, G.; Ruiz, M.J. Beauvericin induced cytotoxicity via ROS production and mitochondrial damage in Caco-2 cells. Toxicol. Lett. 2013, 222, 204-211. [CrossRef] [PubMed]

15. Zhang, K.; Tan, X.; Li, Y.; Liang, G.; Ning, Z.; Ma, Y.; Li, Y. Transcriptional profiling analysis of Zearalenone-induced inhibition proliferation on mouse thymic epithelial cell line 1. Ecotox. Environ. Safe 2018, 153, 135-141. [CrossRef]

16. Zouaoui, N.; Mallebrera, B.; Berrada, H.; Abid-Essefi, S.; Bacha, H.; Ruiz, M.J. Cytotoxic effects induced by patulin, sterigmatocystin and beauvericin on CHO-K1 cells. Food Chem. Toxicol. 2016, 89, 92-103. [CrossRef]

17. Juan-García, A.; Tolosa, J.; Juan, C.; Ruiz, M.J. Cytotoxicity, Genotoxicity and Disturbance of Cell Cycle in HepG2 Cells Exposed to OTA and BEA: Single and Combined Actions. Toxins 2019, 11, 341. [CrossRef]

18. Ferrer, E.; Juan-García, A.; Font, G.; Ruiz, M.J. Reactive oxygen species induced by beauvericin, patulin and zearalenone in CHO-K1 cells. Toxicol. In Vitro 2009, 23, 1504-1509. [CrossRef]

19. Mallebrera, B.; Font, G.; Ruiz, M.J. Disturbance of antioxidant capacity produced by beauvericin in CHO-K1 cells. Toxicol. Lett. 2014, 226, 337-342. [CrossRef]

20. Stockmann-Juvala, H.; Mikkola, J.; Naarala, J.; Loikkanen, J.; Elovaara, E.; Savolainen, K. Oxidative stress induced by fumonisin B1 in continuous human and rodent neural cell cultures. Free Radic. Res. 2004, 38, 933-942. [CrossRef]

21. Zhang, X.; Boesch-Saadatmandi, C.; Lou, Y.; Wolffram, S.; Huebbe, P.; Rimbach, G. Ochratoxin A induces apoptosis in neuronal cells. Genes Nutr. 2009, 4, 41-48. [CrossRef]

22. Zingales, V.; Fernández-Franzón, M.; Ruiz, M.J. Sterigmatocystin-induced cytotoxicity via oxidative stress induction in human neuroblastoma cells. Food Chem. Toxicol. 2020, 136, 110956. [CrossRef]

23. Stanciu, O.; Juan, C.; Miere, D.; Loghin, F.; Mañes, J. Occurrence and co-occurrence of Fusarium mycotoxins in wheat grains and wheat flour from Romania. Food Control. 2017, 73, 147-155. [CrossRef]

24. Juan, C.; Berrada, H.; Mañes, J.; Oueslati, S. Multi-mycotoxin determination in barley and derived products from Tunisia and estimation of their dietary intake. Food Chem. Toxicol. 2017, 103, 148-156. [CrossRef] [PubMed]

25. Oueslati, S.; Berrada, H.; Mañes, J.; Juan, C. Presence of mycotoxins in Tunisian infant foods samples and subsequent risk assessment. Food Control. 2017, 84, 362-369. [CrossRef]

26. EFSA. Guidance on harmonised methodologies for human health, animal health and ecological risk assessment of combined exposure to multiple chemicals. EFSA J. 2019, 17, 5634. [CrossRef]

27. Ruiz, M.J.; Franzova, P.; Juan-García, A.; Font, G. Toxicological interactions between the mycotoxins beauvericin, deoxynivalenol and T-2 toxin in CHO-K1 cells in vitro. Toxicon 2011, 58, 315-326. [CrossRef] [PubMed]

28. Juan-García, A.; Juan, C.; König, S.; Ruiz, M.J. Cytotoxic effects and degradation products of three mycotoxins: Alternariol, 3-acetyl-deoxynivalenol and 15-acetyl-deoxynivalenol in liver hepatocelular carcinoma cells. Toxicol. Lett. 2015, 235, 8-16. [CrossRef]

29. Juan-García, A.; Juan, C.; Manyes, L.; Ruiz, M.J. Binary and tertiary combination of alternariol, 3-acetyl-deoxynivalenol and 15-acetyl-deoxynivalenol on HepG2 cells: Toxic effects and evaluation of degradation products. Toxicol. In Vitro 2016, 34, 264-273. [CrossRef]

30. Chou, T.C.; Talalay, P. Quantitative analysis of dose-effect relationships: The combined effects of multiple drugs or enzyme inhibitors. Adv. Enzyme Regul. 1984, 22, 27-55. [CrossRef]

31. Chou, T.C. Theoretical basis, experimental design, and computerized simulation of synergism and antagonism in drug combination studies. Pharmacol. Rev. 2006, 58, 621-681. [CrossRef] [PubMed]

32. Tatay, E.; Meca, G.; Font, G.; Ruiz, M.J. Interactive effects of zearalenone and its metabolites on cytotoxicity and metabolization in ovarian CHO-K1 cells. Toxicol. In Vitro 2014, 28, 95-103. [CrossRef] [PubMed]

33. Marin, D.E.; Pistol, G.C.; Bulgaru, C.V.; Taranu, I. Cytotoxic and inflammatory effects of individual and combined exposure of HepG2 cells to zearalenone and its metabolites. N-S. Arch. Pharmacol. 2019, 392, 937-947. [CrossRef] [PubMed]

34. Zheng, N.; Gao, Y.N.; Liu, J.; Wang, H.W.; Wang, J.Q. Individual and combined cytotoxicity assessment of zearalenone with ochratoxin A or $\alpha$-zearalenol by full factorial design. Food Sci. Biotechnol. 2018, 27, 251-259. [CrossRef] [PubMed]

35. Jia, J.; Wang, Q.; Wud, H.; Xiaa, S.; Guoa, H.; Blaženovićc, I.; Zhanga, Y.; Suna, X. Insights into cellular metabolic pathways of the combined toxicity responses of Caco-2 cells exposed to deoxynivalenol, zearalenone and Aflatoxin B1. Food Chem. Toxicol. 2019, 126, 106-112. [CrossRef] [PubMed] 
36. Abid, S.; Bouaziz, C.E.; Golli-Bennour, E.; Ouanes Ben Othmen, Z.; Bacha, H. Comparative study of toxic effects of zearalenone and its two major metabolites $\alpha$-zearalenol and $\beta$-zearalenol on cultured human Caco-2 cells. J. Biochem. Mol. Toxic. 2009, 23, 233-243. [CrossRef] [PubMed]

37. Ruiz, M.J.; Festila, L.E.; Fernandez, M. Comparison of basal cytotoxicity of seven carbamates in CHO-K1 cells. Environ. Toxicol. Chem. 2006, 88, 345-354. [CrossRef]

(C) 2020 by the authors. Licensee MDPI, Basel, Switzerland. This article is an open access article distributed under the terms and conditions of the Creative Commons Attribution (CC BY) license (http://creativecommons.org/licenses/by/4.0/). 